\title{
OBSERVATORY PUBLICATIONS AND THEIR SIGNIFICANT ROLE IN ASTRONOMICAL LIBRARIES
}

\author{
Kinga Kaminska \\ Library of Warsaw University Observatory \\ Aleje Ujazdowskie 4 \\ PL-00-478 Warszawa, Poland
}

The Library of Warsaw University Observatory is a small one, but it is one of the oldest astronomical libraries in Poland. The library collection has been gathered almost since the beginning of the Warsaw Observatory, that is since 1825. Although a large part of our collection was burned during the Second World War, the remaining part contains many unique items. Scholars doing research in the area of the history of astronomy often find our collection very helpful in their work.

Observatory publications play a significant role in my library. In general, we have limited possibilities for buying publications with hard currency. Therefore, any free publications obtained by my library constitute an extremely valuable source of information about new research and discoveries all over the world.

I find the situation (or the tendency towards the situation) in which the number of observatories editing and distributing their publications gradually decreasing really unfortunate. The libraries distribute, or tend to distribute, a list of publications instead of the publications themselves. This, in my opinion, is absolutely insufficient.

There are publications from forty-one countries in my library - approximately five hundred titles - most of them however, as I have mentioned already, either have ceased publication, or are no longer being sent to us.

The cataloguing in my library is abbreviated. We register only the basic bibliographic details; that is, title, imprint (place and publisher), opening date of the library's holdings, and the last issue if the publication has ceased. Updating is not being done in the catalogue itself. In order to find out the latest issue held, one has to go to the shelf. Therefore from my point of view, clear and simple numbering of the publications is extremely important and it makes their arrangement easier for the readers and library staff as well. There is a special room for observatory publications, where they are arranged alphabetically in the following order: country; name of observatory, institution, or place within the country; and title of publication of the particular institution. The last criterion of arrangement is, of course, always issue number. The only exceptions are those specific issues that are astronomical catalogues, which are shelved in the room with other catalogues and atlases, and are considered to be and registered as catalogues. There is a note in the catalogue 
that tells where that particular issue can be found. Ephemera are stored until their validity expires.

Finally, being the librarian of a small library in a small country, I can only say that, although acquisition of smaller numbers of materials creates fewer problems in comparison to the problems being discussed here, it is obvious that the more publications we get, the better and fuller information we can provide to our astronomers. We librarians of small libraries are always grateful for any publications generously sent to us by our bigger and wealthier colleagues. 